\title{
Are managers also 'crafting leaders'? The link between organizational rank, autonomy, and job crafting
}

\begin{abstract}
Although research has examined the role leaders may play in shaping job re-design behaviors among their subordinates, little is known about the way managers craft their jobs as compared to other employees. In two crosssectional studies we tested whether organizational rank affects the frequency of job crafting (H1), and to what extent this relationship is mediated via perceived autonomy (H2). Study $1(N=267)$ demonstrated that managers craft their jobs more frequently than non-managers by increasing structural job resources and seeking challenges at work. We also showed that autonomy explains the relationship between organizational rank and the frequency of increasing structural and social job demands, as well as seeking challenges. However, managers did not craft their jobs by decreasing job demands more often than regular employees. In Study $2(N=262)$ we replicated this pattern of results, subsequently demonstrating that managers with shorter tenure use their autonomy to craft their jobs via decreasing job demands. We discuss the contributions and potential implications of these results.
\end{abstract}

Key words: autonomy, positive psychology, managers, job crafting, organizational tenure, proactivity

"I'm not going to spend the rest of my life working my $a^{* *}$ off and getting nowhere just because I followed rules that I had nothing to do with setting up."

Tess McGill in 'Working Girl' movie (1988)

Tess, a working-class Staten Island woman employed by one of Manhattan's Financial District companies, feels that her current work tasks and responsibilities do not match her talent and ambitions. As a secretary working in the mergers and acquisitions department of a Wall Street investment bank, she does not merely answer the phone or take notes during business meetings, but uses this opportunity to learn something about the world of finances. At one point, having read an article in The New York Post, she comes up with a brilliant idea that would save a large company from a foreign takeover.

The above description tells a story of someone whofaced with a person-job misfit-chooses to transform certain aspects of their job and adapt it to their own preferences. Tess attempts to learn new things at work, uses her capabilities to the fullest, and initiates a new project unrelated to her core responsibilities. She actively takes control of an unsatisfactory situation to bring about positive change: a more desirable career, tailored to Tess's personality and competences. This act of job customization is in line with what scholars have labeled job crafting (Berg, Dutton, \& Wrzesniewski, 2008; Tims \& Bakker, 2010; Wrzesniewski \& Dutton, 2001). A growing number of papers on this phenomenon (over 90,000 hits in Google Scholar; accessed: July 2016) indicate that job crafting attracts the attention of scholars and practitioners.

Berg and colleagues (2008) suggest that job crafting takes place in many organizations and across distinct professions. It seems intuitive that the amount of such customization should vary by the type of appointment. Interestingly, to the best of our knowledge, no previous studies have examined whether one's rank in the

\footnotetext{
* SWPS University of Social Sciences and Humanities, Faculty in Sopot, Polna 16/20, 81-745 Sopot, Poland

** Department of Psychology, SWPS University of Social Sciences and Humanities, Warsaw, Poland

Corresponding author: Marta Anna Roczniewska
} 
organizational hierarchy allows to predict the frequency of engaging in job crafting behaviors. While researchers acknowledged that leaders can influence work environment to affect the frequency of job crafting among their subordinates (Wang et al., 2016; Wrzesniewski \& Dutton, 2001), little is known about how a managerial position actually affects the type and frequency of one's job crafting.

The aim of this paper is twofold. First, we wish to address the above-mentioned literature gap by exploring the relationships between one's rank in the organizational hierarchy (managers vs. non-managers) and the frequency of job crafting. Subsequently, we attempt to identify a mechanism responsible for this relationship. Job customization requires certain levels of autonomy (Tims \& Bakker, 2010), which may depend on one's rank in the company. Hence, individuals in higher positions in the organizational hierarchy (managers) may have more means to craft their jobs to their preferences than individuals in lower positions (subordinates). We expect this relationship to be mediated via increased autonomy. Finally, the extent to which managers engage in job crafting may depend on their tenure. Namely, it seems justified that individuals change their jobs more often at the early stages of their career; later on, the job becomes adjusted to their preferences, so the need for crafting ceases.

This paper attempts to address the literature gap on crafting among people holding higher organizational ranks. We test two possible conditions affecting the frequency of crafting: autonomy and tenure. To this date, these variables haven't been used jointly to explain why and when managers engage in job redesign behaviors To accomplish these goals, we begin by discussing job crafting's theoretical underpinnings, including a review of its antecedents and consequences. We then explain the rationale behind our hypotheses, paying particular attention to the role of autonomy in shaping job redesign behaviors among managers. A description of two conducted studies is then followed by careful consideration of their contribution and limitations. We close our paper with a discussion of future directions of research and advice for practitioners.

\section{Theory and Hypotheses}

\section{What Is Job Crafting?}

Wrzesniewski and Dutton (2001) introduced the concept of job crafting to denote the process whereby employees shape and change their jobs in three possible ways. Firstly, individuals may initiate changes in the form, scope or number of their tasks, e.g., inventing a new way of filing documents. Secondly, employees may modify the extent or nature of their social interactions at work, e.g., holding online meetings with team members instead of traditional office meetings. Finally, people may engage in cognitive crafting, for instance, they can change their perception of the purpose of their job, e.g., a calling rather than a means of earning money.

Tims and Bakker (2010) invoked the job demandsresources theory (Demerouti, Bakker, Nachreiner, \& Schaufeli, 2001) to propose another perspective for conceptualizing the job crafting phenomenon. They define job crafting as the set of changes that individuals make in their job demands and resources to achieve a better fit between their job and personal abilities, needs and preferences (Tims \& Bakker, 2010). According to JD-R model, job demands refer to those aspects of the job that require physical or psychological effort, and are therefore associated with certain physiological and psychological costs (Bakker \& Demerouti, 2007). Examples of demands are emotionally demanding interactions with clients or high work pressure. On the other hand, job resources are associated with the aspects of the job that support employees in achieving work goals, reducing job demands, and stimulating personal growth (Bakker \& Demerouti, 2007). These could be skill variety, performance feedback, and learning opportunities. The main assumption of JD-R model is that the interactions of specific job demands and specific job resources determine employee well-being; for instance, high job demands and low job resources produces burnout, whereas increased challenge demands and job resources evoke engagement (Bakker \& Demerouti, 2007). Consequently, given the JD-R framework, to craft their jobs employees may increase their structural and social job resources, e.g., by asking their supervisors for feedback. Moreover, they may seek challenging job demands, e.g., by participating in a new project. They may also engage in reducing hindering job demands, for instance, by avoiding colleagues who are a source of distress.

Job crafting and other job-redesign behaviors differ in that in the former employees engage in crafting on their own initiative, without consulting the changes with their supervisors. For example, idiosyncratic deals require specific arrangements that are negotiated with the organization. Additionally, the aim of job crafting is to increase one's job fit, and thus it should primarily serve the individual, rather than the organization. A different proactivity action-voice-is targeted at suggesting the changes to organizational functioning that principally serve the company rather than the individual expressing their concerns (for further comparisons with other proactive job behaviors see Tims \& Bakker, 2010; Wrzesniewski \& Dutton, 2001). Interestingly, job crafting behaviors may end up unnoticed by the supervisors (Wrzesniewski \& Dutton, 2001), while still affecting the individuals who engage in such behaviors, as well as their colleagues (Tims, Bakker, Derks, \& van Rhenen, 2013).

\section{What Are the Consequences of Job Crafting?}

Although individuals engage in altering the characteristics of their jobs mostly to fulfill their personal goals, job crafting behaviors may benefit both employees and their companies. Job crafting is linked with higher levels of job satisfaction and commitment (Leana, Appelbaum, \& Shevchuk, 2009). Recent findings suggest that individuals optimize their person-job fit by crafting their job demands and resources; as a consequence, the fit affects employees' job meaningfulness (Tims, Derks, \& Bakker, 2016). Moreover, job crafting influences employees' work engagement and job performance (Tims, 
Bakker, \& Derks, 2015); these positive consequences are observable at the individual as well as team level (Tims et al., 2013). Interestingly, collaborative job crafting relates to task performance especially among the less experienced employees (Leana et al., 2009). Seeking job resources is related to higher employee creativity at work, which happens via increased work engagement and flourishing (Demerouti, Bakker, \& Gevers, 2015). Ghitulescu (2006) observed that job crafting correlates with reduced absenteeism. Engaging in job alteration behaviors can also prove helpful during turbulent times. Task and relational crafting can help employees deal with organizational transformation (Kira, Balkin, \& San, 2012).

However, to paint a more accurate picture of the job crafting phenomenon, one should mention its potentially dysfunctional aspects, which are highlighted when the changes introduced by an employee are not in line with organizational goals (Berg, Dutton, \& Wrzesniewski, 2013). To begin with, employees may introduce tasks to their daily activities that could distract them from pursuing their main responsibilities. Moreover, decreasing the level of hindering job demands has been linked with counterproductive work behaviors (Demerouti, Bakker, \& Halbesleben, 2015). When employees reduce their workload, it follows that their colleagues are likely to end up on the receiving end of such a change. Scholars have also investigated more sinister motives behind job crafting that may result from certain personality traits, e.g., narcissism linked to seeking social resources and reducing job demands (Roczniewska \& Bakker, 2016).

\section{Who Engages in Job Crafting and When?}

The results of qualitative and quantitative research by Berg, Dutton, and Wrzesniewski (2008) suggest that job crafting behaviors emerge in a wide array of jobs. Multiple studies to date have demonstrated that the type and amount of crafting one engages in depend on certain organizational and personal characteristics. A proactive personality is a clear predictor of engaging in job crafting behaviors: proactive workers are more likely to increase their job resources, e.g. ask for autonomy, create skill variety, and attend training (structural resources), ask for feedback or help (social resources), and set themselves challenges (Bakker, Tims, \& Derks, 2012). Cynicism, on the other hand, correlates negatively with job crafting (Tims \& Bakker, 2010). Job crafting also depends on individual differences in selfregulation; namely, promotion-oriented individuals craft their jobs by increasing job resources and challenges, whereas prevention-oriented individuals prefer to decrease the level of hindering job demands (Brenninkmeijer \& HekkertKoning, 2015). While extraverts and narcissists seek social job resources, higher scores in psychoticism are linked with fewer crafting behaviors that involve asking for feedback or advice from colleagues at work (Roczniewska \& Bakker, 2016). Demographic variables also relate to the frequency of engaging in job crafting behaviors. More frequent crafting has been observed among individuals with higher education (Leana et al., 2009), and among younger employees (Bipp \& Demerouti, 2014).
As for situational predictors, Wrzesniewski and Dutton (2001) identify task interdependence as a negative predictor of job crafting, and the level of freedom at work as a positive predictor. Indeed, work discretion (the ability to make choices and decisions regarding one's job) relates to both individual and collaborative job crafting (Leana et al., 2009). Other studies demonstrated that a high level of daily job demands combined with a high level of daily job autonomy correlates with seeking job resources more actively and with fewer attempts at reducing job demands on a daily basis (Petrou, Demerouti, Peeters, Schaufeli, \& Hetland, 2012). Wrzesniewski and Dutton (2001) argued that excessive supervision could inhibit job alteration attempts. Wang, Demerouti, and Bakker (2016) suggest that job crafting can be enhanced when leaders empower their subordinates by building a climate of trust and support.

\section{Why Would Managers Craft More?}

As demonstrated above, the characteristics of both the individuals and the work environment play a significant role in boosting the rate of employees engaging in job crafting. Several organizational variables listed in the previous section (freedom, task independence, work discretion) relate to autonomy at work. Hackman and Oldham (1976) define autonomy as the liberty to organize work, make decisions and determine methods to achieve goals. Autonomy is a very important work characteristic that has demonstrated to affect employees' satisfaction, commitment, and motivation; moreover, it is linked with lower role ambiguity, reduced interest in quitting, and higher performance (Spector, 1986). Increased autonomy at work has also been associated with more opportunities to cope with stressful work situations (Bakker, Demerouti, \& Euwema, 2005).

Wrzesniewski and Dutton (2001) posit that the opportunity to autonomously choose what tasks to undertake and how to perform them is a prerequisite for job crafting. Indeed, studies have shown that day-level autonomy is linked with day-level seeking of resources, which, combined with high work pressure, decreases the likelihood of reducing job demands (Petrou et al., 2012). There is no denying that managers have more control over their job environment and typically experience a higher degree of autonomy compared to regular employees. This, in turn, presents them with more opportunities to modify certain aspects of their jobs. Accordingly, a qualitative study conducted by Berg, Wrzesniewski, and Dutton (2010) demonstrated that lower-rank employees believe to have relatively less freedom to craft their jobs, since job design limits them to the "prescribed ends as well as the means for how to do their work" (p. 168). Given this line of reasoning we expect the following:

H1. Managers craft their jobs more frequently than nonmanagers by (a) increasing structural job resources, (b) increasing social job resources, (c) seeking challenges, and (d) reducing job demands.

H2. The relationship between one's rank in the organizational hierarchy and the frequency of job crafting is mediated by their perceived autonomy at work. 


\section{Study 1}

\section{Method}

Participants and procedure

The study was conducted both online and offline. In the first case, the participants $(N=180)$ completed questionnaires implemented into Google Forms, while the participants in the direct procedure $(n=87)$ used the pen-and-paper tool. All participants took part in the study voluntarily and received no remuneration for their participation. There were 105 individuals holding managing positions (39.3\%). We introduced the study as a survey on 'The Perception of Work'. The sample consisted of 93 men (34.8\%) and 174 women (65.2\%). Participants' mean age was $34.49(S D=8.78)$. Participants worked an average of 39.52 hours per week $(S D=10.97)$. The sample was diverse in terms of market sectors ( $73 \%$ private, $27 \%$ public).

\section{Measures}

Job crafting was assessed using four subdimensions of the Polish version (Roczniewska \& Retowski, 2016) of the job crafting scale originally developed by Tims, Bakker, and Derks (2012). The dimensions of the scale are: increasing structural job resources (e.g. "I try to develop my capabilities"; $\alpha=.83$ ), increasing social job resources (e.g. "I ask colleagues for advice"; $\alpha=.67$ ), increasing challenging job demands (e.g. "When there is not much to do at work, I see it as a chance to start new projects"; $\alpha=.84$ ) and decreasing hindering job demands (e.g. "I make sure that my work is mentally less intense"; $\alpha=.75)$. Job crafting was also measured as one construct; $\alpha=.78$. Each dimension of the scale consists of five items, except for decreasing hindering job demands, which includes six items. Items were rated on a 5-point scale, ranging from 1 (never) to 5 (very often).

Perceived autonomy was assessed with a three-item scale (Bakker, Demerouti, \& Verbeke, 2004) created on the basis of Karasek's (1985) job content instrument. The scale was translated into Polish by one of the authors of this manuscript. Example items are "I can decide on my own how to execute my work" and "In my job, I have the freedom to decide how to do my work"; $\alpha=.90$ ). Items were rated on a 5-point scale, ranging from 1 (never) to 5 (always).

To determine one's organizational rank, we asked the participants whether they held a managing position of any sort (e.g., a supervisor, a foreman, a director, a chief, etc.) at the time. We coded their answers into two categories: $0=$ no and $1=$ yes.

\section{Analysis strategy}

To verify the hypotheses about the relationship between the rank in the organizational hierarchy and the frequency of job crafting (H1) as mediated via job autonomy (H2), we used mediation analyses in the regression model. The rank in the organizational hierarchy ( $0=$ non-manager, $1=$ manager $)$ acted as a predictor, four types of job crafting-as dependent variables, and perceived autonomy-as a mediator (see Figure 1).

We conducted mediation analyses using the PROCESS macro for SPSS (Hayes, 2013). We conducted four independent mediations using Model 4 (Hayes, 2013) for four types of job crafting. To test the significance of indirect effects, we used a $95 \%$ bootstrap confidence interval based on 5,000 bootstrap samples. The bootstrap procedure estimates more accurate confidence intervals of indirect effects, since it resamples from the data set and estimates the indirect effect in every new sample (MacKinnon, Lockwood, \& Williams, 2004). According to the procedure, the mediation effect is considered significant when the average assessment of indirect effect is within a 95-percent confidence interval that does not contain zero (Preacher \& Hayes, 2004). As recommended by Hayes (2013), in the text and tables we report the nonstandardized values of the correlation coefficient.

\section{Results and Discussion}

Table 1 presents means, standard deviations, and intercorrelations of the study variables. The reliability coefficients (Cronbach's alpha) are on the diagonal.

Table 1 demonstrates that the correlations between one's organizational rank and job crating were positive and statistically significant for increasing structural resources ( $r=.14, p=.021$ ) and for challenging job demands $(r=.28, p<.001)$. There was no significant relationship between the organizational rank and increasing social resources ( $r=.04$, not significant [NS]), or with decreasing hindering job demands $(r=.00$, NS). The correlation between organizational rank and autonomy was positive and statistically significant $(r=.44, p<.001)$. Moreover, autonomy correlated significantly with three out of four job

\section{Figure 1}

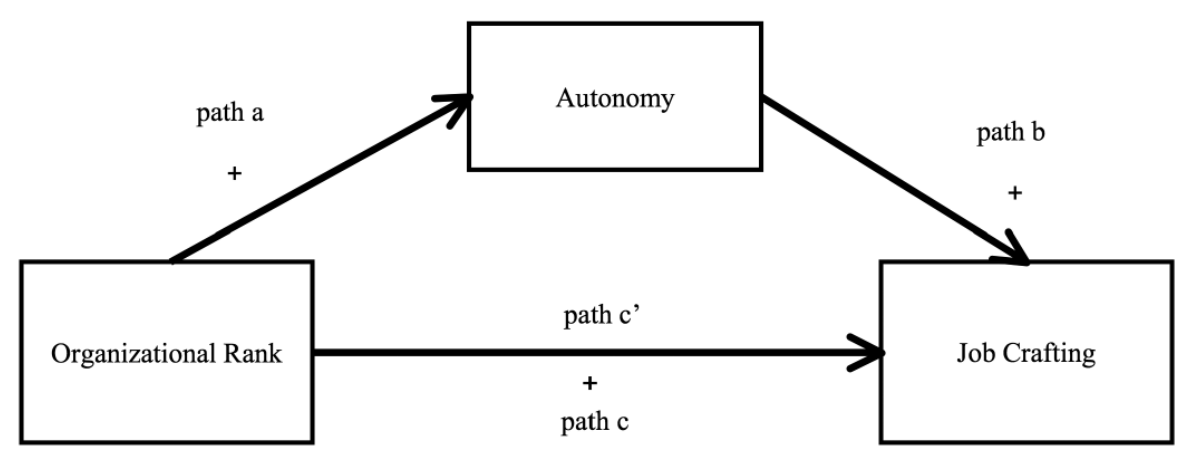


Table 1. Means (M), Standard deviations (SD), and Zero-order Correlations Between Variables in Study 1

\begin{tabular}{|c|c|c|c|c|c|c|c|c|}
\hline & \multicolumn{2}{|c|}{ Descriptives } & \multicolumn{6}{|c|}{ Correlations } \\
\hline & $M$ & $S D$ & $\mathbf{R}$ & A & IStR & ISoR & SC & RHD \\
\hline Organizational Rank $(\mathrm{R})^{\mathrm{a}}$ & - & - & - & & & & & \\
\hline Autonomy (A) & 3.93 & 0.88 & $.44 * * *$ & $(.88)$ & & & & \\
\hline Increasing Structural Resources (IStR) & 4.20 & 0.64 & $.14 *$ & $.47 * * *$ & (.64) & & & \\
\hline Increasing Social Resources (ISoR) & 3.18 & 0.78 & .04 & $.18 * *$ & $.25 * * *$ & $(.78)$ & & \\
\hline Increasing Challenges (SC) & 3.53 & 0.84 & $.28 * *$ & $.44 * * *$ & $.56 * * *$ & $.34 * * *$ & $(.84)$ & \\
\hline Reducing Hindering Demands (RHD) & 2.90 & 0.78 & -.00 & .01 & -.05 & -.01 & .03 & $(.78)$ \\
\hline
\end{tabular}

Note. $N=267$. Values in parentheses on the diagonal indicate Cronbach's alpha coefficients for scales' reliabilities.

$* * * p<.001, * * p<.01, * p<.05$

a Coding: $0=$ Non-manager, $1=$ Manager

crafting behaviors: increasing structural resources $(r=.47$, $p<.001)$, increasing social resources $(r=.18, p=.003)$, and increasing challenging job demands $(r=.44, p<.001)$. There was no significant correlation between autonomy and decreasing hindering job demands $(r=.01$, NS). Table 1 demonstrates significant positive correlations between job crafting behaviors: increasing structural resources and increasing social resources $(r=.25, p<.001)$, increasing structural resources and increasing challenging job demands $(r=.56, p=<.001)$, and finally-increasing social resources and increasing challenging job demands $(r=.34, p=<.001)$. There were no statistically significant correlations between decreasing hindering job demands and other kinds of job crafting.

Table 2 presents the results of mediation analyses in the relationship between organizational rank and the four job crafting behaviors as mediated by autonomy. To verify Hypothesis 1, we examined the relationship between rank in the organizational hierarchy and the frequency of job crafting in its four forms (paths c) ${ }^{1}$. As presented in Table 2, results were in line with Hla, indicating that managers craft their work more often by increasing structural resources (Point

Table 2. The Mediation Analysis for Autonomy in the Relationship Between Organizational Rank and Job Crafting in Study 1

\begin{tabular}{|c|c|c|c|c|}
\hline \multirow[b]{2}{*}{ Autonomy (M) } & \multicolumn{4}{|c|}{ Organizational Rank (X) } \\
\hline & $\begin{array}{l}\text { Increasing Structural } \\
\text { Resources }(Y)\end{array}$ & $\begin{array}{l}\text { Increasing Social } \\
\text { Resources }(Y)\end{array}$ & $\begin{array}{c}\text { Increasing Challenges } \\
\text { (Y) }\end{array}$ & $\begin{array}{l}\text { Reducing Hindering } \\
\text { Demands (Y) }\end{array}$ \\
\hline $\mathrm{X}->\mathrm{M}(\mathrm{a})$ & $\begin{array}{c}0.79 ; 95 \% \\
\text { CI }[0.59 ; 0.98]\end{array}$ & $\begin{array}{c}0.79 ; 95 \% \\
\text { CI }[0.59 ; 0.98]\end{array}$ & $\begin{array}{c}0.79 ; 95 \% \\
\text { CI }[0.59 ; 0.98]\end{array}$ & $\begin{array}{c}0.79 ; 95 \% \\
\text { CI }[0.59 ; 0.98]\end{array}$ \\
\hline $\mathrm{M}->\mathrm{Y}(\mathrm{b})$ & $\begin{array}{c}0.37 ; 95 \% \\
\text { CI }[0.28 ; 0.46]\end{array}$ & $\begin{array}{c}0.18 ; 95 \% \\
\text { CI }[0.06 ; 0.30]\end{array}$ & $\begin{array}{c}0.38 ; 95 \% \\
\text { CI }[0.26 ; 0.49]\end{array}$ & $\begin{array}{c}0.01 ; 95 \% \\
\text { CI }[-0.11 ; 0.13]\end{array}$ \\
\hline $\mathrm{X}->\mathrm{Y}(\mathrm{c})$ & $\begin{array}{c}0.18 ; 95 \% \\
\text { CI }[0.03 ; 0.34]\end{array}$ & $\begin{array}{c}0.0695 \% \\
\text { CI }[-0.14 ; 0.25]\end{array}$ & $\begin{array}{c}0.47 ; 95 \% \\
\text { CI }[0.27 ; 0.67] \\
\end{array}$ & $\begin{array}{c}-0.00 ; 95 \% \\
\text { CI }[-0.19 ; 0.19]\end{array}$ \\
\hline $\mathrm{X}(\mathrm{M})->\mathrm{Y}\left(\mathrm{c}^{\prime}\right)$ & $\begin{array}{c}-0.11 ; 95 \% \\
\text { CI }[-0.26 ; 0.05]\end{array}$ & $\begin{array}{c}-0.08 ; 95 \% \\
\text { CI }[-0.30 ; 0.13]\end{array}$ & $\begin{array}{c}0.17 ; 95 \% \\
\text { CI }[-0,03 ; 0.38]\end{array}$ & $\begin{array}{c}-0.01 ; 95 \% \\
\text { CI }[-0.22 ; 0.20]\end{array}$ \\
\hline Indirect Effect & $\begin{array}{c}0.29 ; 95 \% \\
\text { CI }[0.20 ; 0.40]\end{array}$ & $\begin{array}{c}0.14 ; 95 \% \\
\text { CI }[0.06 ; 0.24]\end{array}$ & $\begin{array}{c}0.30 ; 95 \% \\
\text { CI }[0.20 ; 0.42]\end{array}$ & $\begin{array}{c}0.01 ; 95 \% \\
\text { CI }[-0.08 ; 0.11]\end{array}$ \\
\hline
\end{tabular}

$\mathrm{X}=$ predictor (organizational rank), $\mathrm{M}=$ mediator (autonomy), $\mathrm{Y}=$ dependent variable (job crafting)

$\mathrm{a}-\mathrm{c}^{\prime}=$ paths

$\mathrm{CI}=$ confidence interval

Lower and upper bounds given in square brackets

\footnotetext{
${ }^{1}$ Due to the uneven number of participants in the groups (105 managers, 162 non-managers), we conducted a parallel analysis using a nonparametric test (Mann-Whitney U) to compare ranks between managers and non-managers for the 4 job crafting behaviors. The pattern in the obtained results was the same.
} 
Estimate $[\mathrm{PE}]=0.18$; Bias Corrected $[\mathrm{BC}]$ 95\% Confidence Intervals [CI] [0.03; 0.34]), and with $H 1 c$, demonstrating that they seek challenging job demands $(\mathrm{PE}=0.47 ; \mathrm{BC} 95 \%$ CI $[0.27 ; 0.67])$ more often than non-managers. However, results did not confirm $H 1 b$, which stated that managers craft they work more often by increasing social resources $(\mathrm{PE}=0.06 ; \mathrm{BC} 95 \% \mathrm{CI}[-0.14 ; 0.25])$, or Hld predicting a significant relationship with reducing hindering job demands ( $\mathrm{PE}=-0.00$; BC 95\% CI $[-0.19 ; 0.19])$.

To verify Hypothesis 2, we examined whether the relationship between rank in the organizational hierarchy and the frequency of job crafting is mediated by perceived autonomy at work. Table 2 demonstrates that the relationship between rank in the organizational hierarchy and perceived autonomy (path a) was significant $(\mathrm{PE}=0.79$; $\mathrm{BC} 95 \%$ CI $[0.59 ; 0.98])$. Subsequently, the relationship between perceived autonomy was significant for three out of four job crafting behaviors (path $\mathrm{b}$ ): increasing structural resources $(\mathrm{PE}=0.37$; $\mathrm{BC} 95 \% \mathrm{CI}[0.28 ; 0.46])$, increasing social resources $(\mathrm{PE}=0.18$; $\mathrm{BC} 95 \% \mathrm{CI}[0.06 ; 0.30])$ and seeking challenging job demands $(\mathrm{PE}=0.38 ; \mathrm{BC} 95 \% \mathrm{CI}$ $[0.26 ; 0.49])$. There was no significant correlation between perceived autonomy and reducing hindering job demands $(\mathrm{PE}=0.01 ; \mathrm{BC} 95 \% \mathrm{CI}[-0.11 ; 0.13])$.

Including autonomy as a mediator in the relationship between the organizational rank and job crafting demonstrates that the direct relationship between these variables was not significant (path c') for increasing structural resources $(\mathrm{PE}=-0.11 ; \mathrm{BC} 95 \% \mathrm{CI}[-0.26 ; 0.05])$, seeking challenging job demands $(\mathrm{PE}=0.17 ; \mathrm{BC} 95 \% \mathrm{CI}$ $[-0.03 ; 0.38])$ or increasing social resources $(\mathrm{PE}=-0.08$; BC 95\% CI $[-0.30 ; 0.13])^{2}$. As expected, indirect effects were significant for increasing structural job resources $(\mathrm{PE}=0.29 ; \mathrm{BC} 95 \% \mathrm{CI}[0.20 ; 0.40])$, increasing social job resources $(\mathrm{PE}=0.14 ; \mathrm{BC} 95 \% \mathrm{CI}[0.06 ; 0.24])$, and increasing challenging job demands $(\mathrm{PE}=0.30 ; \mathrm{BC} 95 \%$ CI $[0.20 ; 0.42])$, indicating that the mediation of autonomy occurs between the organizational rank and these three job crafting behaviors.

The results of Study 1 supported the majority of our assumptions. First, in line with Hypotheses 1a and $1 \mathrm{c}$, we demonstrated that managers craft their jobs more frequently by increasing their structural job resources and challenges at work than non-managers. This pattern is consistent with the conclusions of the qualitative study by Berg, Wrzesniewski, and Dutton (2010), where managers reported to be more active in redesigning their jobs. Proactivity is inscribed in the role of leaders (see e.g., historiometric research on presidents: Deluga, 1998), who are more inclined and better equipped to shape their organizational environment than non-leaders.
Surprisingly, our findings did not confirm Hypothesis $1 \mathrm{~b}$, indicating that managers do not craft their work more often than other employees by increasing social job resources (e.g., asking others for feedback or advice on one's work). One reason for this might be that a managerial position in the organizational hierarchy results in a relatively independent and individual mode of work, which makes one less likely to consult decisions or ask for advice. Similarly, asking for feedback can be difficult, since high-ranking employees often have no immediate supervisors. Another explanation may invoke cultural specificities affecting managerial styles. Since Poland is a country scoring high in the power distance dimension (Hofstede, 2011), a typical supervisor would tell subordinates what to do rather than take their ideas and decisions into account.

Our results demonstrate that higher organizational ranks provide more opportunities for job crafting. Based on in-depth interviews with managers and non-managers, we assumed that subordinates believe to have less freedom and power to change certain aspects of their jobs compared with their supervisors (Berg et al., 2010). Indeed, in line with Hypothesis 2, our study demonstrated that the relationship between occupying a managerial position and more frequent job crafting is mediated through perceived autonomy at work. When autonomy is introduced into the model, the direct relationship between organizational rank and crafting ceases to be significant, which suggests that being a manager allows to explain crafting behaviors only to the extent to which it is associated with perceived autonomy. The relationship between autonomy and job crafting has been established previously (Petrou et al., 2012). This study demonstrates that work discretion can serve as a mechanism explaining why certain organizational positions or roles allow for more crafting than others.

Interestingly, managers tend to craft more than nonmanagers through perceived autonomy at work with regard to three out of four crafting behaviors listed by Tims and Bakker (2010). Namely, they seek structural and social jobs resources, as well as challenging job demands more often than individuals occupying lower positions in the organizational hierarchy; however, contrary to Hypothesis 1d, there seems to be no difference between these groups with regard to reducing hindering demands (e.g., decreasing workload or emotional demands at work). Therefore, it would seem that to tailor their jobs to their own purposes managers would employ expansion-oriented rather than withdrawal-oriented behaviors (seeking, rather than reducing). Indeed, an additional analysis ${ }^{3}$ revealed that when engaging in job crafting, managers most frequently choose to increase their structural job demands, then to

\footnotetext{
2 Traditional Sobel tests were conducted to determine whether the reduction in the effect of the independent variable, after including the mediator in the model, was significant and-therefore-whether the mediation effect is statistically significant. Their results were identical to those of the bootstrapping procedure.

3 A repeated-measures GLM analysis for managers revealed that the frequency of crafting depends on its type, $F(3,312)=74.00 ; p<.001$. Managers crafted their jobs most frequently by increasing structural jobs resources $(M=4.31, S D=0.62)$, then-by increasing challenges $(M=3.82, S D=0.84)$, next-by increasing social job resources, $(M=3.21, S D=0.84)$ and finally by reducing job demands $(M=2.90, S D=0.87)$. All of the pairwise comparisons (with Bonferroni adjustment) were statistically significant.
} 
seek challenges, then to increase social job resources, and finally - to reduce their job demands.

Although autonomy appears to form a precondition for job crafting, it does not necessarily mean that the additional freedom and independence that managers have necessarily translates into more frequent job redesign behaviors. Once people make changes to their job so that its design meets their expectations to a greater degree, in all likelihood they will engage in job crafting less frequently. Therefore, reaping the benefits of work autonomy to engage in job crafting may depend on one's period of employment with a particular company (organizational tenure). In other words, supervisors whose organizational tenure has been relatively shorter may use their autonomy to change their jobs to a larger extent, while more experienced managers may not utilize their autonomy to engage in more crafting, as they may deem further changes unnecessary. Therefore, we predict that organizational tenure, defined as the number of years working for a particular employer, moderates the extent to which autonomy explains crafting among managers. Namely:

H3. Only for the employees with a relatively short organizational tenure autonomy mediates the relationship between being a manager and job crafting behaviors.

\section{Study 2}

\section{Method}

\section{Participants and procedure}

The procedure was analogous to the procedure employed in Study 1; however, this time all participants $(N=280)$ took part in an online study. As in the previous study, all participants were volunteers. The sample consisted of 102 men (36.4\%) and 178 women (63.6\%), with a mean age of 33.98 years $(S D=8.60)$. There were 104 individuals holding a managerial position (36.4\%). In line with Study 1, the sample was diverse in terms of market sectors $(71.1 \%$ - private; $27.1 \%$ - public; $1.8 \%$ - unknown). On average, the participants worked
41.36 hours per week $(S D=14.32)$, and their mean organizational tenure was 5.11 years $(S D=6.27)$. We excluded from analysis the participants who did not report their organizational tenure $(n=6)$ and those whose tenure was shorter than half a year (cf. Tims et al., 2012) $(n=18)$.

\section{Measures}

As in Study 1, we employed Polish adaptations of the Job Crafting Scale (Tims et al., 2012) and the Autonomy Scale (Bakker, Demerouti, \& Verbeke, 2004). Moreover, we asked the participants about their organizational rank. To verify our new hypothesis, we added an extra question about participants' organizational tenure. The question was mandatory.

\section{Analysis strategy}

To verify Hypothesis 3 about the moderating role of tenure on the relationships observed previously, we employed a moderated mediation analysis, in which organizational rank acted as a predictor, job crafting types - as a dependent variables, and autonomy at workas a mediator. Organizational tenure moderated path b (see Figure 2).

To test Hypothesis 3 we employed a moderated mediation analysis (Model 14) using the PROCESS macro for SPSS (Hayes, 2013). We calculated a 95\% confidence interval (CI) based on 5,000 bootstrapping samples for computing conditional indirect effects at various values of the moderator. To determine the moderation of mediation we analyzed the index of moderated mediation (Hayes, 2015). An interval estimate of the index of moderated mediation provides an inferential test as to whether the indirect effect is linearly related to the moderator (Hayes, 2015). If the CI excludes zero, one can infer that the relationship between the indirect effect and the moderator differs from zero, evidencing moderated mediation. Conversely, if the CI includes zero, there is no evidence for moderated mediation (Hayes, 2015). We conducted a separate analysis for each kind of job crafting behavior.

\section{Figure 2}

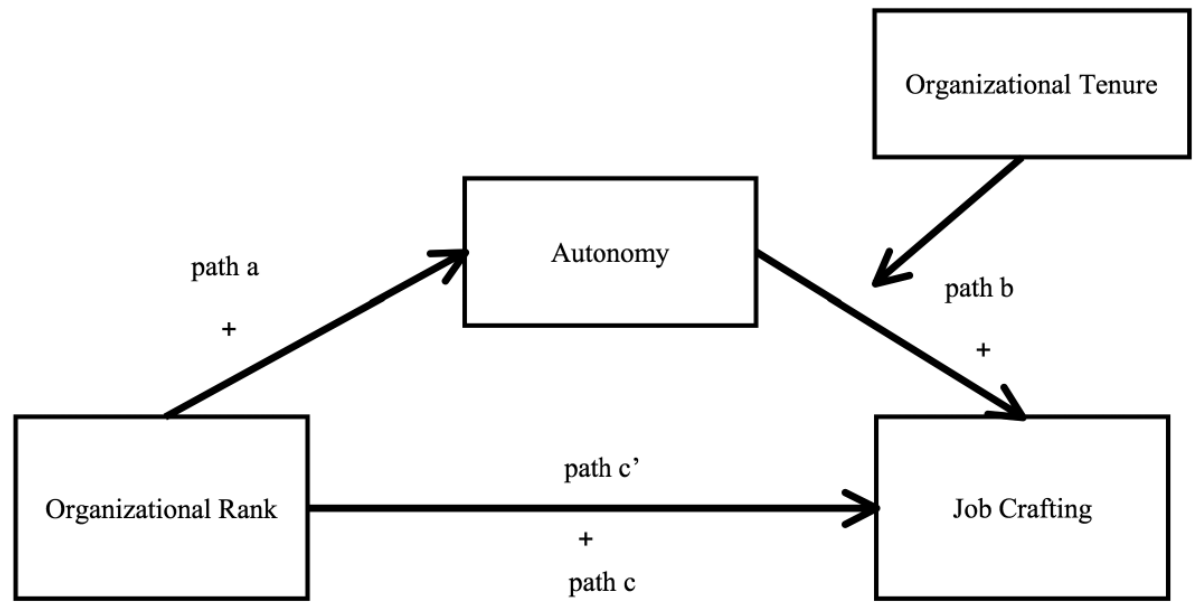




\section{Results and Discussion}

Table 3 presents the means, standard deviations, and intercorrelations of the variables in Study 2. The reliability coefficients (Cronbach's alpha) are on the diagonal.

The pattern of correlations shows that managers craft their work more often than other employees by increasing structural resources $(r=.16, p=.012)$ and challenging job demands $(r=.26, p<.001)$, but not through other types of crafting behaviors (NS). A correlation between one's organizational rank and work autonomy was positive and significant ( $r=.19, p=.002)$, indicating that managers experience more work discretion than non-managers. Moreover, autonomy relates positively to three out of four job crafting behaviors: increasing structural resources $(r=.47, p=.001)$, increasing social resources $(r=.18$, $p=.004)$, and increasing challenging job demands $(r=.35, p<.001)$. There was no significant correlation between autonomy and decreasing hindering job demands $(r=.04$, NS). Organizational tenure does not correlate with organizational rank $(r=.07$, NS) or autonomy $(r=-.09, \mathrm{NS})$; however, we observed significant negative correlations between organizational tenure and increasing structural $(r=-.14, p=.031)$ and social resources $(r=-.23$, $p<.001)$, indicating that the longer an individual worked for one organization, the less frequently they crafted their resources. Correlations between organizational tenure and increasing challenging job demands $(r=-.04, \mathrm{NS})$ or decreasing hindering job demands $(r=-.01$, NS) were not significant. Furthermore, there were significant correlations between job crafting behaviors: increasing structural and social resources $(r=.34, p<.001)$, increasing structural resources and challenging job demands $(r=.67, p<.001)$, increasing social resources and challenging job demands $(r=.39, p<.001)$, increasing social resources and decreasing hindering job demands $(r=.12, p=.045)$. Correlations between decreasing hindering job demands and the other two crafting behaviors: increasing structural resources $(r=-.03, \mathrm{NS})$ and increasing challenging job demands $(r=-.07, \mathrm{NS})$ were not significant.

To examine Hypothesis 3, we conducted 4 independent moderated mediations. Their results are presented in Table 4.

Table 3. Means (M), Standard deviations $(S D)$, and Zero-order Correlations Between Variables in Study 2

\begin{tabular}{|c|c|c|c|c|c|c|c|c|}
\hline & \multicolumn{2}{|c|}{ Descriptives } & \multicolumn{6}{|c|}{ Correlations } \\
\hline & $M$ & $S D$ & $\mathbf{R}$ & $\mathbf{A}$ & $\mathbf{T}$ & IStR & ISoR SC & RHD \\
\hline Organizational Rank (R) ${ }^{\mathrm{a}}$ & - & - & - & & & & & \\
\hline Autonomy (A) & 4.05 & 0.95 & $.19 * *$ & $(.91)$ & & & & \\
\hline Tenure $(\mathrm{T})$ & 5.44 & 0.34 & .07 & -.09 & - & & & \\
\hline $\begin{array}{l}\text { Increasing Structural Resources } \\
\text { (IStR) }\end{array}$ & 4.20 & 0.64 & $.16^{*}$ & $.47 * * *$ & $-.14 *$ & $(.79)$ & & \\
\hline Increasing Social Resources (ISoR) & 2.99 & 0.92 & .10 & $.18 * *$ & $-.23 * * *$ & $.34 * * *$ & $(.78)$ & \\
\hline Increasing Challenges (SC) & 3.60 & 0.85 & $.26 * * *$ & $.35 * * *$ & -.04 & $.67 * * *$ & $.39 * * *(.82)$ & \\
\hline $\begin{array}{l}\text { Reducing Hindering Demands } \\
\text { (RHD) }\end{array}$ & 2.77 & 0.73 & -.10 & .04 & -.01 & -.03 & $.12 *$ & $(.70)$ \\
\hline
\end{tabular}

Note. $N=262$. Values in parentheses on the diagonal indicate Cronbach's alpha coefficients for scales' reliabilities.

$* * p<.001, * * p<.01, * p<.05$

a Coding $0=$ Non-manager, $1=$ Manager

Table 4. The Indices of Moderated Mediation for the Effect of Organizational Rank on Job Crating Through Autonomy with Organizational Tenure as a Moderator

\begin{tabular}{lccc}
\hline \multicolumn{1}{c}{ Dependent Variable } & Index & SE & BC 95\% CI \\
\hline Increasing Structural Resources & -0.003 & 0.003 & {$[0.010 ; 0.002]$} \\
\hline Increasing Social Resources & -0.004 & 0.004 & {$[-0.012 ; 0.003]$} \\
\hline Increasing Challenges & -0.003 & 0.005 & {$[-0.013 ; 0.005]$} \\
\hline Reducing Hindering Demands & -0.007 & 0.004 & {$[-0.016 ;-0.001]$} \\
\hline
\end{tabular}

$\mathrm{SE}=$ Standard Error

BC 95\% CI = Bias Corrected 95\% Confidence Intervals

Lower and Upper Bounds given in square brackets 
As can be observed, the $95 \%$ bootstrap confidence intervals based on 5,000 bootstrap samples for autonomy as a mediator excluded zero only in the case of reducing job demands. Thus, the indirect effect of organizational rank on decreasing hindering job demands through perceived autonomy at work was negatively moderated by organizational tenure. The negative sign indicates that the indirect effect decreases with an increase in the moderator value. Table 5 demonstrates the indirect effects of autonomy for particular values of the moderator (organizational tenure).

The results demonstrate that only managers with relatively shorter organizational tenure $(<7$ years $)$ craft their jobs through autonomy by reducing hindering demands. As evidenced by Table 5, the relationship is no longer significant for managers who worked for 7 or more years with the same organization, in which case they do not reduce hindering job demands using their autonomy any more often than other employees.

The indices were not significant for the other crafting behaviors, suggesting that in these cases the effect is not moderated by organizational tenure. To verify whether the effect of mediation observed in Study 1 can be replicated here, we tested simple mediation (Model 4).

First, we examined the relationship between organizational rank and the frequency of four job crafting behaviors (paths c). Table 6 shows the results to be in line with $H 1 a$, indicating that managers craft their work more often by increasing structural resources $(\mathrm{PE}=0.20 ; \mathrm{BC}$ $95 \%$ CI $[0.05 ; 0.36])$; as well as with $H 1 c$, demonstrating

Table 5. The Results of Indirect Effects of Autonomy in the Relationship Between Organizational Rank and Reducing Hindering Demands Moderated by Tenure in Study 2

\begin{tabular}{cccc}
\hline Tenure (in years) & PE & SE & BC 95\% CI \\
\hline $1.0^{\mathrm{a}}$ & 0.051 & 0.028 & {$[0.010 ; 0.126]$} \\
\hline $1.5^{\mathrm{b}}$ & 0.048 & 0.027 & {$[0.008 ; 0.119]$} \\
\hline $3.0^{\mathrm{c}}$ & 0.037 & 0.024 & {$[0.003 ; 0.099]$} \\
\hline $7.0^{\mathrm{d}}$ & 0.010 & 0.020 & {$[-.0 .024 ; 0.055]$} \\
\hline $12.0^{\mathrm{e}}$ & -0.025 & 0.028 & {$[-.0 .092 ; 0.023]$} \\
\hline
\end{tabular}

Percentiles $={ }^{a} 10$ th, ${ }^{b} 25$ th, ${ }^{c} 50$ th, ${ }^{d} 75$ th, ${ }^{e 90}$ th

$\mathrm{PE}=$ Point Estimates

$\mathrm{SE}=$ Standard Error

BC 95\% CI = Bias Corrected 95\% Confidence Intervals

Lower and Upper Bounds given in square brackets

Table 6. The Mediation Analysis for Autonomy in the Relationship Between Organizational Rank and Job Crafting in Study 2

\begin{tabular}{|c|c|c|c|c|}
\hline \multirow[b]{2}{*}{ Autonomy (M) } & \multicolumn{4}{|c|}{ Organizational Rank (X) } \\
\hline & $\begin{array}{l}\text { Increasing Structural } \\
\text { Resources }(\mathbf{Y})\end{array}$ & $\begin{array}{l}\text { Increasing Social } \\
\text { Resources (Y) }\end{array}$ & $\begin{array}{c}\text { Increasing Challenges } \\
\text { (Y) }\end{array}$ & $\begin{array}{l}\text { Reducing Hindering } \\
\text { Demands }(Y)\end{array}$ \\
\hline \multirow{2}{*}{$X->M(a)$} & $0.38 ; \mathrm{BC} 95 \%$ & $0.38 ; \mathrm{BC} 95 \%$ & $0.38 ; \mathrm{BC} 95 \%$ & $0.38 ; \mathrm{BC} 95 \%$ \\
\hline & CI $[0.14 ; 0.61]$ & CI $[0.14 ; 0.61]$ & CI $[0.14 ; 0.61]$ & CI $[0.14 ; 0.61]$ \\
\hline \multirow{2}{*}{$\mathrm{M}->\mathrm{Y}(\mathrm{b})$} & $0.31 ; \mathrm{BC} 95 \%$ & $0.16 ; \mathrm{BC} 95 \%$ & $0.28 ; \mathrm{BC} 95 \%$ & $0.05 ; \mathrm{BC} 95 \%$ \\
\hline & CI $[0.23 ; 0.38]$ & CI $[0.04 ; 0.28]$ & CI $[0.18 ; 0.38]$ & CI $[-0.05 ; 0.14]$ \\
\hline \multirow{2}{*}{$X->Y(c)$} & $0.20 ; \mathrm{BC} 95 \%$ & $0.18 ; \mathrm{BC} 95 \%$ & $0.44 ; \mathrm{BC} 95 \%$ & $-0.15 ; \mathrm{BC} 95 \%$ \\
\hline & CI $[0.05 ; 0.36]$ & CI $[-0.05 ; 0.41]$ & CI $[0.24 ; 0.65]$ & CI $[-0.33 ; 0.03]$ \\
\hline \multirow{2}{*}{$\mathrm{X}(\mathrm{M})->\mathrm{Y}\left(\mathrm{c}^{\prime}\right)$} & $0.09 ; \mathrm{BC} 95 \%$ & $0.12 ; \mathrm{BC} 95 \%$ & $0.34 ; \mathrm{BC} 95 \%$ & $-0.17 ; \mathrm{BC} 95 \%$ \\
\hline & CI $[-.0 .06 ; 0.24]$ & CI $[-0.11 ; 0.35]$ & CI $[0.14 ; 0.54]$ & CI $[-0.35 ; 0.02]$ \\
\hline \multirow{2}{*}{ Indirect Effect } & $0.11 ; \mathrm{BC} 95 \%$ & $0.06 ; \mathrm{BC} 95 \%$ & $0.10 ; \mathrm{BC} 95 \%$ & $0.02 ; \mathrm{BC} 95 \%$ \\
\hline & CI $[0.05 ; 0.19]$ & CI $[0.01 ; 0.14]$ & CI $[0.04 ; 0.19]$ & CI $[-0.01 ; 0.07]$ \\
\hline
\end{tabular}

$\mathrm{X}=$ predictor (organizational rank), $\mathrm{M}=$ mediator (autonomy), $\mathrm{Y}=$ dependent variable (job crafting)

$\mathrm{a}-\mathrm{c}^{\prime}=$ paths

$\mathrm{CI}=$ confidence interval

Lower and upper bounds given in square brackets 
that they seek challenging job demands $(\mathrm{PE}=0.44 ; \mathrm{BC}$ $95 \%$ CI $[0.24 ; 0.65])$ more often than non-managers. We did not confirm $H 1 b$, which stated that managers craft their work more often by increasing social resources $(\mathrm{PE}=0.18$; BC $95 \%$ CI $[-0.05 ; 0.41])$, or H1d, which predicted the relationship to be significant for reducing hindering job demands ( $\mathrm{PE}=-0.15$; BC 95\% CI [-0.33; 0.03]).

It follows from Table 6 that the relationship between organizational rank and autonomy (path a) was positive and significant, suggesting that managers have more autonomy than non-managers ( $\mathrm{PE}=0.38$; $\mathrm{BC} 95 \% \mathrm{CI}[0.14 ; 0.61])$. Subsequently, we examined the relationships between autonomy and four job crafting behaviors (paths b). The paths were positive and significant for increasing structural resources $(\mathrm{PE}=0.31 ; \mathrm{BC} 95 \% \mathrm{CI}[0.23 ; 0.38])$, increasing social resources $(\mathrm{PE}=0.16 ; \mathrm{BC} 95 \% \mathrm{CI}[0.04 ; 0.28])$, and seeking challenging job demands ( $\mathrm{PE}=0.28$; $\mathrm{BC} 95 \%$ CI $[0.18 ; 0.38])$. The relationship was not significant for reducing hindering job demands $(\mathrm{PE}=0.05 ; \mathrm{BC} 95 \% \mathrm{CI}$ $[-0.05 ; 0.14])$.

The direct effects (path c') were not significant for structural resources $(\mathrm{PE}=0.09 ; \mathrm{BC} 95 \% \mathrm{CI}[-0.06 ; 0.24]$ and increasing social resources $(\mathrm{PE}=0.12 ; \mathrm{BC} 95 \% \mathrm{CI}[-0.11$; $0.35])^{4}$. Indirect effects for structural resources $(\mathrm{PE}=0.11$; BC 95\% CI [0.05; 0.19]) and increasing social resources $(\mathrm{PE}=0.06 ; \mathrm{BC} 95 \% \mathrm{CI}[0.01 ; 0.14])$ were significant, indicating the occurrence of mediation. In the case of seeking challenges, both the direct $(\mathrm{PE}=0.34 ; \mathrm{BC} 95 \% \mathrm{CI}[0.14$; $0.54])$ and indirect effect $(\mathrm{PE}=0.10 ; \mathrm{BC} 95 \%$ CI $[0.04$; $0.19]$ ) were significant, demonstrating that the relationship between organizational rank and seeking challenges can both be direct, and mediated through autonomy.

Our results partially confirmed our assumptions. In Hypothesis 3 we expected that more frequent crafting of one's job through increased autonomy would be typical only of managers with relatively shorter organizational tenure, since the managers with longer tenure have had enough time to adjust their jobs to their needs and preferences. However, this observation demonstrated to be true only in the case of decreasing hindering job demands. We propose the following explanation. Firstly, using autonomy to decrease hindering job demands by managers with shorter organizational tenure may be due to the increased need to feel safe and secure in the position they occupy, which, in turn, may propel them towards the prevention style of coping with difficulties (Brenninkmeijer \& Hekkert-Koning, 2015). Secondly, shorter tenure may imply a relatively lower level of competence and reduced ability to deal with a person-position misfit in an approachoriented way only.

In Study 2 we replicated all of our findings from Study 1 . The results indicate that managers craft their jobs more often than non-managers. Individuals occupying higher organizational ranks are bound to experience more complexity in their work and hence-need more job resources. Also, due to higher educational and skill requirements for such positions, managers could feel more entitled to define their modus operandi (Leana et al., 2009). Furthermore, once again we demonstrate that it is the autonomy (not the position itself) that allows managers to craft more in an approach-oriented way by increasing both kinds of resources-structural and social, as well as by seeking job challenges. In the framework of self-determination theory (Ryan \& Deci, 2002), autonomy is one of the three innate psychological needs that-when satisfied-enhance intrinsic motivation (Gagne \& Deci, 2005); along with other two factors-competence and relatedness-autonomy drives people to be proactive and engaged (Ryan \& Deci, 2000). Therefore, it seems that in the context of work, enhanced autonomy is crucial to motivate and allow employees to craft their jobs (Wrzesniewski \& Dutton, 2001). Interestingly, findings from Studies 1 and 2 did not confirm that autonomy allows managers to craft their jobs by reducing hindering job demands. These findings are consistent with Ryan and Deci's theory (2002) linking autonomy with proactivity. This means that people who enjoy autonomy tend to use approach-oriented strategies of coping rather than avoidance (e.g., reducing demands).

In Study 2, we also demonstrate that the longer the organizational tenure, the less frequently individuals craft their jobs by increasing structural and social resources (regardless of their organizational rank or autonomy). These findings are partially in line with research conducted by Bipp and Demerouti (Study 1; 2014), who established that age acted as a negative predictor of all job crafting behaviors. According to Tims and Bakker (2010) employees change their levels of job demands and job resources in order to align them with their own abilities and preferences. We presume that one reason for less frequent seeking of job resources by employees with longer organizational tenure could be the fact that their needs are satisfied as far as organizational supplies are concerned, because they would have had enough time to adjust their jobs to their preferences. Moreover, employees who work in the same place for a longer period of time possibly no longer exhibit strong motivation to develop their capabilities (increasing structural resources), or ask colleagues for feedback (increasing social resources), since they already feel confident and well-equipped to perform their jobs.

\section{General Discussion}

\section{Study Contribution}

A fit between job and one's preferences and attitudes has various positive consequences for both the employees and their organizations. A meta-analysis on the consequences of person-job fit demonstrated that it relates positively e.g., to employee satisfaction and performance (Kristof-Brown, Zimmerman, \& Johnson, 2005). On the other hand, studies demonstrate that misfit is a stressor which leads to negative consequences, like developing psychosomatic symptoms (Roczniewska

\footnotetext{
4 Sobel tests confirmed that the reduction in the effect of the independent variable is significant after including the mediator in the model.
} 
\& Retowski, 2014). Therefore, it seems worthwhile to examine actions that employees can take on their own initiative to increase their job fit. Scholars have investigated factors that affect job re-design behaviors. These may be related to individual differences, such as personality traits (Roczniewska \& Bakker, 2016) motivational orientation (Brenninkmeijer \& Hekkert-Koning, 2015), or temperament (Bipp \& Demerouti, 2014). In this research, we focused on situational rather than dispositional factors determining the frequency of job redesign behaviors among employees. Findings from our two studies elucidate when the employees tend to be more willing to adjust their work to their needs, as well as the reasons behind their choice of job crafting behaviors.

In our two studies, we indicate that holding a managerial position in an organization may lead to more frequent job crafting; however, we also demonstrate that it is the sense of autonomy that propels managers towards proactively shaping their jobs to a larger degree compared to non-managers. Work autonomy allows managers to craft their jobs in an approach-oriented way by increasing job resources and seeking job challenges. Karasek (1979) introduced the concept of active jobs, denoting professions with high demands (e.g., work pressure) and high levels of control (e.g., leeway to make decisions regarding one's work). He argued that these challenging jobs make employees learn actively and motivate them to develop new behavior patterns. There is no denying that holding a manager's position is an active job with relatively more autonomy and control, but also-consisting of constant role demands. Our study corroborates Karasek's theory by demonstrating that a managerial position increases the likelihood of shaping one's job by seeking more resources and challenges.

Interestingly, Study 2 shows that even without autonomy in the picture, the relationship between being a manager and seeking challenges remains pertinent. This may suggest that, for managers, increasing challenges at work is a desirable style of job crafting, regardless of environmental conditions (such as their level of autonomy). Higher ranks provide managers with greater rights and opportunities to perform constructive actions, but come with greater responsibilities too. This may be related with the key leadership trait, i.e., drive, defined by researchers as ambition, energy, tenacity and initiative (Kirkpatrick \& Locke, 1991). These characteristics may prompt managers to engage in solving difficult problems and taking up challenges, which is in line with the assumptions that an active job empowers employees (Laschinger, Finegan, Shamian, \& Almost, 2001) and fosters skills development (Witte, Verhofstadt, \& Omey, 2007). Therefore, managers may have a stronger need to seek new challenges compared to other employees. Interestingly, studies on the Job Demands-Resources Model (Demerouti et al., 2001) demonstrate that balance between demands and resources is crucial for explaining employees' work engagement, stress levels, and well-being (Bakker \& Demerouti, 2014). In a large study with over 12,000 participants-employees of different occupations (Bakker, van Veldhoven, \&
Xanthopoulou, 2010), researchers discovered that task enjoyment and organizational commitment were highest when employees were confronted with challenging and stimulating tasks, and had sufficient access to job resources. This may be another reason why managers, who-due to their position and work conditions have a better access to job resources-seek more challenges to experience adequate levels of demands.

The pattern of results observed in Study 2 contributes to the literature by showing that organizational tenure has an impact on whether managers use their autonomy to craft their jobs. In Study 1, we were unable to find support for our hypothesis (1d) that managers craft their jobs more often than other employees by reducing hindering demands; however, in Study 2 we observed that managers with shorter organizational tenure benefit from their increased autonomy by avoiding difficulties (hindering job demands). Therefore, when the manager's experience in a given organization is relatively low, they are more likely to use their autonomy to reduce demands of their role. Since reducing the amount of hindering demands can restore employees' energy levels (Bakker $\&$ Costa, 2014), we presume that in the case of managers with shorter organizational tenure, reducing job demands may be triggered by lower levels of competence and ability to deal with high demands involved in their role. Leadership skills develop with experience (e.g., Mumford, Marks, Connelly, Zaccaro, \& Reiter-Palmon, 2000) and as - a result-enable managers to use different methods of coping with difficulties than simple avoidance. With longer organizational tenure, autonomy does not translate into choosing the withdrawal strategy. More experienced managers appear to use their autonomy at work to choose more approach-oriented strategies of job crafting, such as seeking more resources. This is in line with research on flow that links high levels of autonomy and competence to behaviors focused on seeking challenges and opportunities to grow (Nakamura \& Csikszentmihalyi, 2009).

Furthermore, this study contributes to the literature by examining how managers craft their jobs. This is particularly important, because managers are leaders who can model certain behaviors among their subordinates. Therefore, outlining the conditions that allow managers to engage in job crafting and set examples is vital. However, understanding which managerial traits and leadership styles promote crafting among employees is even more important. Considering this, we encourage researchers to examine factors responsible for successful transfer of job crafting behaviors from leaders to subordinates, which may involve trust (Brower, Lester, Korsgaard, \& Dineen, 2009) or Leader-Member Exchange (Dulebohn, Bommer, Liden, Brouer, \& Ferris, 2012).

\section{Study Limitations and Future Research}

Certain limitations of this research must be recognized. Firstly, both studies collected self-report data in a cross-sectional study design (all measures taken at the same time), which raises concerns about commonmethod variance. Furthermore, we cannot make definite 
conclusions about the causal relationships between tested variables, as these should be tested in a longitudinal design. For one thing, it is possible that people with proactive personality are more likely to apply for leadership positions in organizations (Kirkpatrick \& Locke, 1991), and-simultaneously-that they tend to engage in job crafting more frequently (Tims \& Bakker, 2010). Moreover, proactive behaviors may also lead to promotion and explain the positive relationship between crafting and being a manager. These doubts should be addressed in future longitudinal studies.

Another limitation is that we administered an online procedure (in Study 1 - partially; in Study 2 - fully) to collect the data, which translates into lower control over the process. For instance, it may result in multiple submissions by the same individual. However, because no awards were given for participation, we believe this concern may be irrelevant here. On the other hand, online participation lowers researcher's ability to monitor participants' behavior to ensure that subjects are engaged and attentive while filling in the questionnaires. Although the matter of participants' carelessness pertains also in pen-andpaper research (Huang, Liu, \& Bowling, 2015), it can be augmented in online studies.

There may also be alternative explanations as to why managers craft more than non-managers. This active style of behavior is in line with the concept of charismatic leadership (Steyrer, 1998), which states that leaders need to distinguish themselves from competitors through their behaviors to be endorsed by their followers. Hence, this proactive way of job crafting could be more than merely a strategy aimed at redesigning one's job, perhaps, an action fulfilling social expectations. What is interesting, Niessen, Weseler, \& Kostova (2016) found that an increase in job crafting can be predicted by the need for a positive selfimage. Another explanation could be derived from the fact that holding a managing position equips one with power, which has certain psychological consequences. Keltner and colleagues (2003) have proposed that power enhances approach-related behaviors; this could explain why managers seek more structural resources. At the same time, power increases egocentricity (Galinsky, Magee, Ena Inesi, \& Gruenfeld, 2006), which would predict that individuals do not reach out to others (social resources). Finally, power is related to sensation-seeking and risk-taking (Anderson \& Galinsky, 2006; Strużyńska-Kujałowicz, 2013); this aspect could be explanatory of why managers increase challenging job demands and do not report to decrease hindrance demands. Given these alternative explanations (social expectations and power), in future studies it is recommended to test them against autonomy as possible mediators.

Another limitation may result from the way organizational rank was operationalized in this study by coding it into two dimensions only (managers vs. nonmanagers). For instance, participants may have differed with regards to the management level (first-line managers vs. middle managers vs. top managers). It could be that the frequency of increasing social job resources is lower for employees in the highest managerial positions, like CEOs (as compared to middle- or lower-level managers), because such individuals lack supervisors to gain feedback from or ask for help. Moreover, the size of the managed team may also differ, affecting supervisor's crafting. For instance, leading a relatively large group seems be more demanding and thus-may not prompt managers to engage in increasing any more challenges at work. Widening the criteria in future studies by differentiating between management levels and the number of the subordinates may bring more understanding to how crafting behaviors and frequency are dependent on organizational rank.

Future studies should also investigate cultural differences as moderators of the relationships observed here. Such dimensions of culture as power distance or individualism (Hofstede, 2011) may influence leadership styles, and thus prompt managers to choose distinct styles of crafting. For instance, we expect that in hierarchical and individualistic cultures increasing social job resources to be less common than in an egalitarian and collectivistic one. Moreover, job autonomy varies across countries (Van Hoorn, 2016), and therefore it may also influence the frequency and type of job crafting among employees.

\section{Practical Implications}

Job crafting behaviors without doubt bring many positive outcomes to organizations, as well as to employees. Therefore, it is worth pointing out how to support such proactive actions. It has become increasingly popular to introduce job crafting interventions and workshops, in which employees learn how to craft their work by seeking resources and challenges. The results demonstrate that job crafting interventions may e.g., lower the amount of negative affect, as well as increase self-efficacy among employees (e.g., Van den Heuvel, Demerouti, \& Peeters, 2015). Importantly, our studies point to the significance of perceived autonomy as a means to actually being able to craft one's job to a larger extent. Therefore, supervisors should be aware that workshops alone may not be sufficient, with the sense of work autonomy playing a pivotal role in introducing changes to one's job. Notably, we demonstrated that autonomy translates into positive job crafting, namely: seeking more resources and challenges, rather than avoiding difficulties at work. We believe these results call for encouraging proactivity through empowering employees.

\section{Concluding Remarks}

In this paper we address the literature gap on a link between organizational rank and job crafting behaviors. We demonstrate that autonomy allows managers to craft more frequently (as compared to individuals holding lower organizational positions) by increasing job resources and challenging demands. Moreover, managers with shorter organizational tenure use their increased autonomy to reduce hindering job demands. These findings add to the growing body of research on antecedents of job crafting in organizations. To the best of our knowledge, no previous 
studies have investigated the joint effects of autonomy and tenure in predicting crafting among individuals holding higher organizational ranks.

\section{References}

Anderson, C., \& Galinsky, A.D. (2006). Power, optimism, and risk-taking. European Journal of Social Psychology, 36, 511-536. http://doi. org/10.1002/ejsp.324

Bakker, A.B., \& Costa, P.L. (2014). Chronic job burnout and daily functioning: A theoretical analysis. Burnout Research, 1, 112-119. http://doi.org/10.1016/j.burn.2014.04.003

Bakker, A.B., \& Demerouti, E. (2007). The job demands-resources model: state of the art. Journal of Managerial Psychology, 22(3), 309-328. http://doi.org/10.1108/02656710210415703

Bakker, A.B., \& Demerouti, E. (2014). Job demands- resources theory. In C. Cooper, \& P. Chen (Eds.), Wellbeing: A complete reference guide (pp. 37-64). Chichester, UK: Wiley-Blackwell. http://doi. org/10.1002/9781118539415.wbwel1019

Bakker, A.B., Demerouti, E., \& Euwema, M.C. (2005). Job resources buffer the impact of job demands on burnout. Journal of Occupational Health Psychology, 10(2), 170-180. http://doi.org/10.1037/10768998.10.2.170

Bakker, A.B., Demerouti, E., \& Verbeke, W. (2004). Using the job demands-resources model to predict burnout and performance. $\mathrm{Hu}$ man Resource Management, 43(1), 83-104. http://doi.org/10.1002/ hrm.20004

Bakker, A.B., van Veldhoven, M., \& Xanthopoulou, D. (2010). Beyond the Demand-Control Model: Thriving on High Job Demands and Resources. Journal of Personnel Psychology, 9(1), 3-16. http://doi. org/10.1027/1866-5888/a000006

Berg, J., Dutton, J., \& Wrzesniewski, A. (2008). What is Job Crafting and Why Does It Matter? Retrieved from Http://csinvesting.org/wpcontent/uploads/2013/01/Job Crafting-Theory to Prac Tice-Aug 08.pdf. http://doi.org/10.1080/15027570.2012.674245

Berg, J.M., Dutton, J.E., \& Wrzesniewski, A. (2013). Job crafting and meaningful work. In B.J. Dik, Z.S. Byrne, M.F. Steger (Eds), Purpose and meaning in the workplace (pp. 81-104). Washington, DC: American Psychological Association. http://doi.org/10.1037/14183005

Berg, J.M., Wrzesniewski, A., \& Dutton, J.E. (2010). Perceiving and responding to challenges in job crafting at different ranks: When proactivity requires adaptivity. Journal of Organizational Behavior, 31(2-3), 158-186. http://doi.org/10.1002/job.645

Bipp, T., \& Demerouti, E. (2014). Which employees craft their jobs and how? Basic dimensions of personality and employees' job crafting behaviour. Journal of Occupational and Organizational Psychology, 88(4), 631-655. http://doi.org/10.1111/joop.12089

Brenninkmeijer, V., \& Hekkert-Koning, M. (2015). To craft or not to craft The relationships between regulatory focus, job crafting and work outcomes. Career Development International, 20, 147-162. http:// doi.org/10.1108/CDI-12-2014-0162

Brower, H.H., Lester, S.W., Korsgaard, M.A., \& Dineen, B.R. (2009) A Closer Look At Trust Between Managers and Subordinates: Understanding the Effects of Both Trusting and Being Trusted on Subordinate Outcomes. Journal of Management, 35(2)(859), 391-347. http://doi.org/10.1177/0149206307312511

Deluga, R. (1998). American presidential proactivity, charismatic leadership, and rated performance. The Leadership Quarterly, 9(3), 265-291. http://doi.org/10.1016/S1048-9843(98)90030-3

Demerouti, E., Bakker, A.B., \& Gevers, J.M.P. (2015). Job crafting and extra-role behavior: The role of work engagement and flourishing. Journal of Vocational Behavior, 91, 87-96. http://doi.org/10.1016/j. jvb.2015.09.001

Demerouti, E., Bakker, A.B., \& Halbesleben, J.R.B. (2015). Productive and Counterproductive Job Crafting. A Daily Diary Study, 20(4), $457-469$

Demerouti, E., Bakker, A.B., Nachreiner, F., \& Schaufeli, W.B. (2001) The job demands-resources model of burnout. The Journal of Applied Psychology, 86(3), 499-512. http://doi.org/10.1108/0268394 0710733115
Dulebohn, J.H., Bommer, W.H., Liden, R.C., Brouer, R.L., \& Ferris, G.R. (2012). A Meta-Analysis of Antecedents and Consequences of Leader-Member Exchange: Integrating the Past With an Eye Toward the Future. Journal of Management, 38(6), 1715-1759. http:// doi.org/10.1177/0149206311415280

Gagne, M., \& Deci, E.L. (2005). Self-determination theory and work motiviation. Journal of Organizational Behavior, 26, 331-362. http:// doi.org/10.1037/0003-066X.55.1.68

Galinsky, A.D., Magee, J.C., Ena Inesi, M., \& Gruenfeld, D.H. (2006). Power and perspectives not taken. Psychological Science, 17(12), 1068-1074. http://doi.org/10.1111/j.1467-9280.2006.01824.x

Ghitulescu, B. (2006). Shaping tasks and relationships at work: Examining the antecedents and consequences of employee job crafting. Unpublished doctoral dissertation, University of Pittsburgh.

Hackman, J.R., \& Oldham, G.R. (1976). Motivation through the design of work: test of a theory. Organizational Behavior and $\mathrm{Hu}$ man Performance, 16(2), 250-279. http://doi.org/10.1016/00305073(76)90016-7

Hayes, A. (2013). Introduction to mediation, moderation, and conditional process analysis. New York, NY: Guilford. http://doi.org/978-160918-230-4

Hayes, A.F. (2015). An Index and Test of Linear Moderated Mediation. Multivariate Behavioral Research, 50, 1-22. http://doi.org/10.1080 /00273171.2014.962683

Hofstede, G. (2011). Dimensionalizing Cultures: The Hofstede Model in Context. Online Readings in Psychology and Culture, 2(1), 1-26. http://doi.org/http://dx.doi.org/10.9707/2307-0919.1014

Huang, J.L., Liu, M., \& Bowling, N.A. (2015). Insufficient effort responding: Examining an insidious confound in survey data. Journal of Applied Psychology, 100(3), 828-845. http://doi.org/10.1037/ a0038510

Karasek, R. (1985). Job content questionnaire and user's guide. Lowell: University of Massachusetts.

Karasek, R.A. (1979). Job Demands, Job Decision Latitude, and Mental Strain: Implications for Job Redesign. Administrative Science Quarterly, 24(2), 285-308. http://doi.org/10.2307/2392498

Keltner, D., Gruenfeld, D.H., \& Anderson. (2003). Power approach and inhibition. Psychological Review, 110(2), 265-284. http://doi.org/ http://dx.doi.org/10.1037/0033-295X.110.2.265

Kira, M., Balkin, D.B., \& San, E. (2012). Authentic Work and Organizational Change: Longitudinal Evidence from a Merger. Journal of Change Management, 12(1), 31-51. http://doi.org/10.1080/146970 17.2011.652374

Kirkpatrick, S.A., \& Locke, E.A. (1991). Leadership: do traits matter? Academy of Management Executive, 5(2), 48-60. http://doi. org/10.5465/AME.1991.4274679

Kristof-Brown, A.L., Zimmerman, R.D., \& Johnson, E.C. (2005). Consequences of individuals' fit at work: A meta-analysis of person-job, person-organization, person-group, and person-supervisor fit. $\mathrm{Per}$ sonnel Psychology, 58(2), 281-342. http://doi.org/10.1111/j.17446570.2005.00672.x

Laschinger, H.K., Finegan, J., Shamian, J., \& Almost, J.M. (2001). Testing Karasek's demand-control model in restructured healthcare settings: effect of job strain on staff nurses' quality of work life. Journal of Nursing Administration, 31, 233-243. http://doi. org/10.1080/14702430601135560

Leana, C., Appelbaum, E., \& Shevchuk, I. (2009). Work Process and Quality of Care in Early Childhood Education: The Role of Job Crafting. Academy of Management Journal, 52(6), 1169-1192. http://doi.org/10.5465/AMJ.2009.4708465

MacKinnon, D.P., Lockwood, C.M., \& Williams, J. (2004). Confidence limits for the indirect effect. Multivariate Behavioral Research, 39(1), 99-128. http://doi.org/10.1207/s15327906mbr3901

Mumford, M.D., Marks, M.A., Connelly, M.S., Zaccaro, S.J., \& Reiter-Palmon, R. (2000). Development of Leadership Skills: Experience and Timing. Leadership Quarterly, 11(1), 87-114. http://doi. org/10.1016/S1048-9843(99)00044-2

Nakamura, J., \& Csikszentmihalyi, M. (2009). Flow theory and research. In S.J. Lopez, C.R. Snyder (Eds.), Oxford handbook of positive psychology 2nd ed (pp. 195-206). Oxford: Oxford University Press. http://doi.org/10.1093/oxfordhb/9780195187243.013.0018

Niessen, C., Weseler, D., \& Kostova, P. (2016). When and why do individuals craft their jobs? The role of individual motivation and work 
characteristics for job crafting. Human Relations, 69(6), 12871313. http://doi.org/10.1177/0018726715610642

Petrou, P., Demerouti, E., Peeters, M.C.W., Schaufeli, W.B., \& Hetland, J. (2012). Crafting a job on a daily basis: Contextual correlates and the link to work engagement. Journal of Organizational Behavior, 33(8), 1120-1141. http://doi.org/10.1002/job.1783

Preacher, K.J., \& Hayes, A.F. (2004). SPSS and SAS procedures for estimating indirect effects in simple mediation models. Behavior Research Methods, Instruments, \& Computers, 36(4), 717-731. http:// doi.org/10.3758/BF03206553

Roczniewska, M., \& Bakker, A.B. (2016). Who Seeks Job Resources, and Who Avoids Job Demands? The Link Between Dark Personality Traits and Job Crafting. The Journal of Psychology, 150(8), 10261045. http://doi.org/10.1080/00223980.2016.1235537

Roczniewska, M., \& Retowski, S. (2014). The role of job satisfaction in the person-organization fit relationship, in terms of goal pursuit strategies, and mental health. Medycyna Pracy, 65(5), 621-631. http://doi.org/10.13075/mp.5893.00152

Roczniewska, M., \& Retowski, S. (2016). Polska adaptacja Skali Przeksztatcania Pracy [Polish adaptation of the Job Crafting Scale]. Manuscript in preparation.

Ryan, R.M., \& Deci, E.L. (2000). Self-determination theory and the facilitation of intrinsic motivation, social development, and well-being. American Psychologist, 55(1), 68-78. http://doi.org/10.1037/0003066X.55.1.68

Ryan, R.M., \& Deci, E.L. (2002). An overview of self-determination theory. An organismic-dialectical perspective. In E.L. Deci, \& R.M. Ryan (Eds.), Handbook of Self-Determination Research (pp. 3-33). Rochester, NY: The University of Rochester Press.

Spector, P.E. (1986). Perceived control by employees: A meta-analysis of studies concerning autonomy and participation at work. Human Relations, 39(11), 1005-1016. http://doi.org/10.1177/00187267 8603901104

Steyrer, J. (1998). Charisma and the Archetypes of Leadership. Organization Studies, 19(5), 807-828. http://doi.org/10.1177/017084 069801900505

Strużyńska-Kujałowicz, A. (2013). Władza a postrzeganie i podejmowanie ryzyka [Power, risk perception and risk taking]. Przeglad Psychologiczny, 56(3), 279-299.
Tims, M., \& Bakker, A.B. (2010). Job crafting: Towards a new model of individual job redesign. SA Journal of Industrial Psychology, 36(2), 1-9. http://doi.org/10.4102/sajip.v36i2.841

Tims, M., Bakker, A.B., \& Derks, D. (2012). Development and validation of the job crafting scale. Journal of Vocational Behavior, 80(1), 173-186. http://doi.org/10.1016/j.jvb.2011.05.009

Tims, M., Bakker, A.B., \& Derks, D. (2013). The Impact of Job Crafting on Job Demands, Job Resources, and Well-Being. Journal of Occupational Health Psychology, 18(2), 230-240. http://doi. org/10.1037/a0032141

Tims, M., Bakker, A.B., \& Derks, D. (2014). Job crafting and job performance: A longitudinal study. European Journal of Work and Organizational Psychology, 24(6), 914-928. http://doi.org/10.1080/1359 432X.2014.969245

Tims, M., Bakker, A.B., Derks, D., \& van Rhenen, W. (2013). Job Crafting at the Team and Individual Level: Implications for Work Engagement and Performance. Group \& Organization Management, 38(4), 427-454. http://doi.org/10.1177/1059601113492421

Tims, M., Derks, D., \& Bakker, A.B. (2016). Job crafting and its relationships with person-job fit and meaningfulness: A three-wave study. Journal of Vocational Behavior, 92, 44-53. http://doi.org/10.1016/j. jvb.2015.11.007

van den Heuvel, M., Demerouti, E., \& Peeters, M.C.W. (2015). The job crafting intervention: Effects on job resources, self-efficacy, and affective well-being. Journal of Occupational and Organizational Psychology, 88(3), 511-532. http://doi.org/10.1111/joop.12128

Van Hoorn, A. (2016). How Much Does Job Autonomy Vary Across Countries and Other Extra-Organizational Contexts? The International Journal of Human Resource Management, 1, 1-44. http://doi. org/10.1080/09585192.2016.1192052

Wang, H.J., Demerouti, E., \& Bakker, A.B. (2016). A review of job crafting research: The role of leader behaviors in cultivating successful job crafters. In S.K. Parker \& U.K. Bindl (Eds.), Proactivity at work. New York, NY: Routledge.

Witte, H. De, Verhofstadt, E., \& Omey, E. (2007). Testing Karasek's learning and strain hypotheses on young workers in their first job. Work \& Stress, 21(2), 131-141. http://doi.org/10.1080/02678370701405866

Wrzesniewski, A., \& Dutton, J.E. (2001). Crafting a job: Revisioning employees as active crafters of their work. Academy of Management Review, 26(2), 179-201. http://doi.org/10.5465/AMR.2001.4378011 